\title{
Determinación de parámetros fisicoquímicos y microbiológicos de la leche en el municipio de Chipaque Cundinamarca y su comercialización (Colombia)
}

\section{Determination of physicochemical and microbiological parameters of milk and its marketing, in Chipaque, Cundinamarca (Colombia)}

\author{
Vanegas $\mathrm{DB}^{1}$ y Martínez $\mathrm{M}^{2}$ \\ ${ }^{1}$ Médica Veterinaria Zootecnista y ${ }^{2}$ Médico Veterinario. Docente, Escuela de \\ Ciencias Animales Universidad de los Llanos
}

manuelmartinezsuarez@hotmail.com

Recibido 14 de septiembre 2011 aceptado 12 de noviembre 2011

\section{RESUMEN}

En el municipio de Chipaque, Cundinamarca, Colombia, las explotaciones lecheras se enmarcan dentro del sistema doble propósito, se parte de razas seleccionadas como tal, siendo la predominante normando, con cruces con Holstein y animales criollos, ordeñando con la presencia del ternero. Es de anotar que la comercialización de la leche continúa realizándose sin tener en cuenta la calidad del producto, pagándose únicamente por volumen, lo que no incentiva un esfuerzo por parte del productor para mejorar la calidad fisicoquímica y microbiológica de este alimento, Con base en las consideraciones anteriores, la Universidad de los Llanos, por medio de sus programas de proyección social y una estudiante propuso, llevar a cabo un diagnóstico en el cual se determinó la calidad de la leche, y las características de su comercialización en Chipaque, para lo cual se identificaron los parámetros constituyentes de la leche y se analizó su comercialización. Para realizar el estudio se aplicaron encuestas a los productores y a los comercializadores de la leche, los resultados fueron que Chipaque tiene aproximadamente 2.300 vacas lactantes dedicadas a la producción comercial de leche bajo el sistema doble propósito y 99 vacas destinadas al sistema de lechería intensiva. La producción diaria de leche es aproximadamente 13.800 litros y un promedio de 6 litros vaca al día, la producción se ve aumenta en la temporada de 
lluvias. La leche se comercializa en un $100 \%$ como leche cruda con destino del $65 \%$ para fábricas de derivados lácteos, el 30\% con intermediarios y un 5\% la vende el productor. A pesar de contar con un porcentaje significativo (7\%) de vacas Holstein el manejo dado es el mismo del sistema doble propósito, ordeño con el ternero al lado y cría de machos y hembras con destete entre los 8 a 13 meses de edad (97\%), solamente el $3 \%$ de los productores desteta al primer día. Es importante resaltar la calidad físico-química de la leche la cual arroja un $12.77 \%$ de sólidos totales y un $87.23 \%$ de agua de constitución.

Palabras clave: Vacas lecheras, análisis de la leche.

\section{ABSTRACT}

In Chipaque, Cundinamarca, Colombia, dairy farms have dual-purpose cattle, the breeds are selected, being the predominant Norman crosses with Holstein and Creole animals, milking the presence of the calf. It should be noted that the marketing of milk continues to be done regardless of the quality of the product, The milk buyers pay only for volume, which does not encourage an effort by the producer to improve physicochemical and microbiological quality of this food, based on foregoing, the University of the Llanos, through its social programs and a student proposed to carry out a diagnosis which determined the quality of milk, and the characteristics of marketing in Chipaque, for which identified the parameters of milk constituents and analyze marketing. For the study surveys were applied to producers and marketers of milk, the results were that Chipaque has about 2.300 lactating cows involved in the commercial production of milk under the dualpurpose system and 99 cows for intensive dairy system. The daily production of milk is approximately 13,800 liters and 6 liters daily cow /per/ day, production and increases in the rainy season. The milk is sold at $100 \%$ as raw milk bound of $65 \%$ for dairy factories, $30 \%$ with intermediate and $5 \%$ sold by the producer. Although they have a significant percentage $(7 \%)$ of Holstein cows given the management system is the same dual purpose, milking and calf rearing side and males and females with weaning between $8-13$ months of age (97\%), only $3 \%$ of producers 
weaned the first day. It is important to emphasize the physical and chemical quality of milk which gives total solids $12.77 \%$ and $87.23 \%$ water of constitution.

Keywords: Dairy cattle, milk testing.

\section{INTRODUCCIÓN}

La producción de leche en Colombia ha sido dinámica, incrementándose a partir de la década de 1970 (1.500 millones/itro), lo cual fue una situación excepcional en los años 80 cuando se implantó el sistema de doble propósito, actualmente se está produciendo 6.600 millones de litros al año. Existen los sistemas especializado y doble propósito de producción de leche. El hato nacional calculado es 26 millones de cabezas, de ellas 6.25 millones está dedicado a la producción de leche, y el $89 \%$ en el sistema de producción doble propósito que contribuye con el 55\% de la producción nacional (Mojica, 2004).

El sistema especializado, se encuentra normalmente en zonas frías de trópico alto, cerca de los centros de consumo, en estas explotaciones la vaca es ordeñada sin la presencia del ternero, descartándose los machos a los pocos días de nacidos, predominan las razas con un alto porcentaje de genes provenientes de Europa, siendo la producción de leche alta. El sistema doble propósito, predomina en zonas alejadas de los centros de consumo y en este sistema tanto machos como hembras son criados con la vaca. El porcentaje de genes Bos indicus es alto y se tienen cruces con razas Bos taurus (Espinel et al., 2005).

\section{ANÁLISIS DE LA SITUACIÓN EN CHIPAQUE}

En el municipio de Chipaque, Cundinamarca, las explotaciones se pueden enmarcar dentro del sistema doble propósito, partiendo de razas seleccionadas como tal, siendo la predominante normando, con cruces con Holstein y animales criollos, ordeñando con la presencia del ternero. Los animales no son suplementados con alimentos concentrados. En esta zona no existen los incentivos como el pago por calidad del producto, lo cual hace que los ganaderos no se esfuercen en ofrecer leche de buena calidad puesto que no se tiene en 
cuenta parámetros como densidad, grasa, proteína y calidad microbiológica. Por las características de las exportaciones y los factores culturales inherentes en este sistema de explotación, es necesaria una participación activa del sector gubernamental, para incentivar sistemas cooperativos, además de una asistencia técnica programada para garantizar el suministro de un producto compatible con los de otras cuencas lecheras (Cámara de comercio, 2011).

En este municipio, la producción de leche se encuentra distribuida en todas sus veredas, a pesar de las buenas vías que posee como la que conduce a la capital del país es necesario en un futuro próximo contar con centros de acopio y tanques de frío que garanticen entregar un producto de buena calidad. La leche es un producto altamente perecedero y al igual que en otras regiones del país se ve afectada por la alta carga microbiológica favorecida por el manejo higiénico deficiente de utensilios y vehículos inadecuados para el transporte, el desconocimiento de normas higiénicas por parte de los manipuladores y transportadores lo cual dificulta la comercialización del producto.

La proyección de la Cadena Láctea está dada por la demanda de leche de alta calidad, lo cual lleva a pensar en unas maneras más tecnificadas de manejo de las explotaciones de ganado lechero para participar en el mercado tanto nacional como internacional. Con este concepto se busca que los productores interesados participen activamente en mejorar sus explotaciones e iniciar la implementación de nuevos sistemas de conservación como los tanques de frío, además adoptar buenas prácticas de manejo (BPM) para lograr una calidad más elevada, lo que conlleva a que el productor pueda exigir incentivos de pago por calidad (Alcaldía de Chipaque 2003-2007).

Frente a los compradores actuales y futuros debe exigirse unos precios justos siendo necesario crear una cultura de cooperativismo para enfrentar los bajos ingresos que atentan contra la estabilidad económica de los productores. Es de anotar que la comercialización de la leche continúa realizándose sin tener en cuenta la calidad del producto, pagándose únicamente por volumen, lo que no incentiva un esfuerzo por parte del productor para mejorar la calidad fisicoquímica 
y microbiológica de este alimento, siendo necesario caracterizar las falencias en la comercialización proponiendo eliminarlas y reforzar los aciertos. Con base a las consideraciones anteriores, se propuso, llevar a cabo los siguientes objetivos con el fin de aportar al mejoramiento de esta situación:

- Determinar la calidad de la leche, y las características de su comercialización en el municipio de Chipaque Cundinamarca.

- Identificar los parámetros constituyentes de la leche y analizar el impacto de la cadena regional láctea.

\section{UBICACIÓN GEOGRÁFICA}

Chipaque se encuentra ubicada en la provincia del oriente de Cundinamarca, en su extensión territorial tiene una superficie de 13.945 hectáreas (ha) definidas así: Zona Urbana 21 has correspondientes al $0.15 \%$ y 13.924 has a la zona rural equivalentes al $99.85 \%$ del territorio, Conformado por 23 veredas y la cabecera municipal. El casco urbano de Chipaque está localizado a los $4^{\circ} 27^{\prime \prime}$ de Latitud Norte y $74^{\circ} 3^{\prime \prime}$ de longitud este, $2400 \mathrm{~m} \mathrm{~s}$. n. m, una distancia de $27 \mathrm{Km}$. de la capital del país Bogotá D.C. y a $81 \mathrm{Km}$ de la ciudad de Villavicencio sobre el eje vial sur-oriental del país (Alcaldía de Chipaque 2003 - 2007).

Su topografía se caracteriza por predominio de moderadas y fuertes pendientes que van del $5 \%$ terreno plano, $30 \%$ terreno ondulado y el $65 \%$ terreno inclinado. Presenta tres pisos térmicos clima medio, frío y páramo, con una temperatura de $14^{\circ} \mathrm{C}$, un promedio anual de precipitaciones de $815 \mathrm{~mm}$. Se definen dos periodos durante el año, uno lluvioso, que comprende de abril a noviembre con el $86.6 \%$ del total anual y uno seco de diciembre a marzo con el $12.4 \%$. Los mantos litológicos que conforman la formación Chipaque son arcillas negras, esquirlas, calizas areniscas y areniscas de grano fino (Alcaldía de Chipaque 2003 - 2007).

\section{COMPONENTES DE LA LECHE}

La leche se compone de agua y sólidos, estos últimos se dividen en no grasos y grasa. Los sólidos no grasos son las proteínas, minerales, vitaminas y 
carbohidratos. Los sólidos totales (Grasos y no grasos), representan el extracto seco (sin agua). La composición media de la leche normal de vaca es la siguiente: Agua $87.5 \%$ y extracto seco $12.5 \%$ del cual el componente graso equivale a un $3.5 \%$ y el extracto seco desengrasado corresponde a un $9.0 \%$ distribuido de la siguiente manera: proteínas $3.5 \%$, lactosa $4.7 \%$, sales minerales $0.8 \%$ completando $100 \%$. La leche contiene además enzimas, vitaminas y ácidos libres (Spreer, 1975).

El agua constituye un medio de soporte para sus componentes sólidos y gaseosos. Los compuestos sólidos de la leche (la materia seca) pueden ser determinados directamente por la aplicación de calor para evaporar la fase acuosa. Un método indirecto para calcular la materia seca se efectúa mediante la relación entre la densidad de la leche y su contenido de grasa. Aplicándose la siguiente fórmula de Richmond, modificada por Kirk et al., (1999).

$\%$ S.T. $=(0.25 \times$ Densidad $)+(1.21 \times \%$ Grasa $)+0.66$

(Usar para densidad los valores milésimales como enteros: Ejemplo si $D=1.032$, usar 32.). Calcular los sólidos totales de una leche arroja el siguiente análisis: Densidad corregida a $15^{\circ} \mathrm{C}=1.032$, grasa $=3.0 \%$. Se aplica la fórmula:

$\%$ Sólidos totales $=(0.25 \times 32)+(1.21 \times 3.0)+0.66$

$\%$ Sólidos totales $=(8)+(3.63)+0.66$

$\%$ Sólidos totales $=12.29 \%$.

Las razas bovinas difieren en la cantidad de grasa que contiene la leche y su composición. La alimentación de las vacas ejerce una gran influencia en este sentido, la grasa se presenta en la leche en forma de glóbulos, los cuales tienden a ubicarse en la superficie. El tamaño de los glóbulos de grasa varía entre 2-10 micras, en general son de 9 micras, dependiendo de la especie y la raza del animal. En la homogenización, los glóbulos reducen su tamaño hasta 1.5 micras, permitiendo que la grasa se distribuya uniformemente, formando una emulsión. El tamaño de los glóbulos homogenizados permite que la ley de atracción de masas produzca una mejor distribución (Martínez, 2003). 
El Ministerio de protección en 2006 y 2008, decretó que de acuerdo al tipo de leche, y teniendo en cuenta el porcentaje de grasa, éstas se clasifican en: Enteras: Grasa $>3.0 \%$, semidescremadas: Grasa $1.5-2.0 \%$ y leches descremadas: Grasa $0.1-0.5 \%$, su contenido de grasa es muy variable, y puede deberse, en el sistema de doble propósito, a aspectos inherentes al animal, como: salud, condición corporal, época de lactancia, edad de la vaca, plano nutricional, raza, medio ambiente climático, y bienestar animal (Martínez. 2003).

El contenido proteico depende fundamentalmente del alimento que consumen los animales lecheros, las principales proteínas de la leche se sintetizan en la glándula mamaria a partir de un conjunto de aminoácidos libres, y proteínas caseinosas y no caseinosas. La caseína tiene múltiples usos gracias a sus cualidades nutritivas y a sus propiedades funcionales (Luquet, 1993.). El contenido de caseína es aproximadamente de $27 \mathrm{~g} / \mathrm{L}$ existiendo varias clases: alfa, beta, gama y delta. La caseína puede ser precipitada por la acción de una enzima denominada quimosina o renina. En las proteínas no caseinosas se encuentra la lactoalbumina, que aumenta en el caso de mastitis y el calostro, las cantidades en leches no pasan de $5 \mathrm{~g} / \mathrm{L}$, que es al $0.5 \%$ (Keating, 1986).

La lactosa, es un disacárido formado por glucosa y galactosa, es el menos variable en la leche y representa el $4,7 \%$ de los sólidos totales, la lactosa es fermentada por las bacterias lácticas produciendo acido láctico, el calor la afecta, en temperaturas por encima de $110^{\circ} \mathrm{C}$ se deshidrata, denominándose lactosa anhidra, y por encima de $130^{\circ} \mathrm{C}$ se produce caramelización (Valerie, 2001). La lactosa limita la producción de leche; es decir que la cantidad de este producto, depende de las posibilidades de síntesis de lactosa en la glándula mamaria (Alais, 1985).

Los minerales en la leche son: potasio, calcio, sodio, fósforo, cloro, flúor, rubidio, sílice, zinc, cobre, hierro, molibdeno, litio, magnesio, manganeso cobalto yodo y níquel. Las sales se encuentran en dispersión siendo las más importantes el fosfato de potasio, calcio y magnesio. También la leche contiene numerosas enzimas, las principales son: grupo hidrolasas: lipasa, fosfatasa, amilasa y lactasa; 
se tiene en el grupo de los oxido reductores, siendo importantes la peroxidasa y la catalasa, las cuales se encuentran en bajas concentraciones permitiendo el crecimiento, mantenimiento y funcionamiento del organismo, la leche figura entre los alimentos que contienen la variedad más completa de vitaminas (Veisseyre, 1990).

Dentro del grupo de las vitaminas liposolubles se tiene Vitamina A, máximo con $500 \mathrm{mg} / \mathrm{L}$, provitamina $D_{2}$ y $D_{3}$ máximo $1 \mathrm{mg} / \mathrm{L}$, vitamina $\mathrm{E}$ con 500 a $1000 \mathrm{mg} / \mathrm{L}$ y finalmente la vitamina $\mathrm{K}$ de la cual solamente hay trazas. Dentro de las hidrosolubles tenemos la vitamina $B_{2}, B_{7}$ y vitamina $C$ (Keating, 1986.) Los gases presentes en la leche son el dióxido de carbono, oxigeno e hidrogeno. Los pigmentos que imparten las coloraciones amarillas a la grasa son alfa y beta carotenos, y la verde azulosa del suelo debido a la riboflavina.

\section{CRITERIOS PARA LA TOMA DE MUESTRAS DE LECHE}

Para realizar esta actividad se aplicaron dos tipos de encuestas: una para productores de leche y otra para comercializadores. En la primera se consideró: identificación del predio, extensión y cultivos (se incluyeron forrajes), vereda, propietario, servicios públicos, distancia al centro de acopio, estado de la vía, animales (número total, vacas lactantes, horras, novillas de vientre y de levante, terneras, terneros, machos de levante, machos de ceba, toros y cruces), otros animales, sanidad del hato (vacunaciones, vermifugaciones); proceso en la producción de leche: ordeño (con o sin ternero), tiempo de lactancia, cantidad producida por época (lluvias y verano), elaboración productos lácteos (cuajada o queso), sanidad donde efectúa el ordeño, deposito y conservación de la leche, personal, y comercialización. En el segundo tipo de encuesta se consideraron los siguientes aspectos: ubicación del centro distribuidor de leche, cantidad vendida y condiciones del producto: pasteurizada, cruda y elaboración de derivados lácteos Con esta información se realizó un estudio seccional cruzado efectuándose un muestreo cuyo nivel primario fue desde la salida del túnel Angelino Garzón hasta la vereda Alto de la Cruz por la carretera que conduce a Cáqueza; otro por la vía hacia Ubaque en donde se encuentran las veredas Cerezos y Nizame (La Idaza); 
igualmente por la vía a une y Cumba, Siecha, Potrero Grande y Caldera; y las veredas aledañas a la cabecera municipal; el segundo nivel de muestreo fueron las fincas con producción de leche comercializable en vías primarias y secundarias dentro de los transectos. Dentro de las fincas el muestreo de vacas comprendió todos los animales en ordeño en el momento de la visita, teniendo en cuenta el minifundismo prevalente en la región. La unidad de muestreo fueron los predios determinados por la fórmula de Martín et al., (1987) así:

$\mathrm{n}=\mathrm{p} X \mathrm{q} X \mathrm{z}^{2} /(\mathrm{EE})^{2}$

$\mathrm{n}=$ numero de predios a evaluar

$\mathrm{p}=\mathrm{a} 0.95$ porcentaje de predios al menos con una vaca productora de leche en los cuartos funcionales

$\mathrm{q}=\mathrm{a} 0.05(1-\mathrm{p})$

$\mathrm{z}=1.96$ nivel de confianza $=0.05$

Error Experimental $=0.06^{2}$

$\mathrm{n}=\left(0.95 \times(1.96)^{2}\right) /(0.06)^{2}$

$n=52$ predios

A 116 vacas de diferentes grupos etarios equivalentes al 10\% de las hembras lactantes en la región, y que correspondió al mayor porcentaje de los cruces y significancia poblacional, se les tomaron muestras de leche para determinar su calidad fisicoquímica en los que se consideran los siguientes aspectos: el transporte de las muestras fueron bajo condiciones de refrigeración teniendo cuidado que la temperatura no fuera superior de $4^{\circ} \mathrm{C}$ hasta la llegada al laboratorio de la planta de lácteos de la Universidad de los llanos. Algunos exámenes se realizaron en el momento de la toma tales como la prueba de mastitis California y la prueba de acidez titulable que determina el porcentaje de acido láctico presente en el producto. Los frascos utilizados fueron Gatorader previamente esterilizados realizándose la toma con mechero para asegurar un envío del producto bajo condiciones asépticas. A las muestras de leche se les analizó: 
-Densidad: Se determinó con el termolactodensimetro de Quevenne ajustado a 15 grados centígrados, contándose con aparatos calibrados por la secretaria de salud de Bogotá.

-Grasa: Se utilizó para esta determinación el método GERBER, los reactivos y materiales en esta prueba son:

- Acido sulfúrico $\mathrm{H}_{2} \mathrm{SO}_{4}$ con densidad de $1.82 \mathrm{~g} / \mathrm{ml}$ y una pureza de $90 \mathrm{a}$ $91 \%$.

- Alcohol amílico con densidad de $0.81 \mathrm{~g} / \mathrm{ml}$.

- Centrifuga con capacidad de trabajo de $2500 \mathrm{rpm}$.

- Butirómetro de Gerber estándar para análisis de leche.

- Técnica: Se deposito en el butirómetro $10 \mathrm{ml}$ de $\mathrm{H}_{2} \mathrm{SO}_{4}$ y luego $11 \mathrm{ml}$ de leche en forma lenta sobre las paredes del recipiente, posteriormente se añadió $1 \mathrm{ml}$ de alcohol amílico y se tapo el butirómetro, luego se agito y se centrifugo a $2500 \mathrm{rpm}$ durante 5 minutos, por último, se hizo la lectura del porcentaje de grasa en la escala graduada del butirómetro.

\section{-Acidez:}

- Reactivos Solución de NaOH 0.1 N Solución de fenolftaleína disuelta al 1\% en alcohol amílico.

- Técnica: Se vertió en un vaso de precipitados $9 \mathrm{ml}$ de leche, a estos se agregó 5 gotas de fenolftaleína y se titulo con $\mathrm{NaOH} 0.1 \mathrm{~N}$ hasta la aparición de un color rosado persistente. Se expreso el resultado como porcentaje de ácido láctico calculándose de la siguiente manera: \% de ácido láctico cantidad en $\mathrm{ml}$ de $\mathrm{NaOH}$ utilizado/10

\section{-Sólidos no grasos:}

- Técnica en la que se utilizó el lactómetro de Bertuzzi el cual determina sólidos no grasos en forma directa. El aparato se compone de un prisma de cuarzo, una lente y una escala de 0 a $14 \%$ con intervalos de 0.2 


\section{-Mastitis sub-clínica:}

- Para determinarla se lavó la ubre con abundante agua y se secó con papel, eliminándose los primeros chorros y se desinfecto la punta del pezón con una solución yodada, utilizando una raqueta para prueba de mastitis debidamente rotulada se extrajeron dos o tres chorros de leche en el sitio indicado para cada cuarto en la raqueta (anteriores derecho e izquierdo, y posteriores izquierdo y derecho) y se le adicionó cantidad igual de reactivo del test mastitis california (CMT) homogenizando al mismo tiempo. Se observó y se hizo la respectiva lectura (Rodríguez, 1988)

Para la determinación de la mastitis sub-clínica se preparó un patrón tiocanato de azul de metileno, y debió ceñirse a cumplir los pasos del protocolo en forma estricta para obtener resultados confiables, la esterilización de los materiales fue primordial para evitar contaminación, así como la manipulación innecesaria. Se tomaron $9 \mathrm{ml}$ de leche por $1 \mathrm{ml}$ de la sustancia patrón, se incubaron observándose los cambios de color de la siguiente manera: Sí cualquiera de las muestras se decoloraba después de una incubación de 30 minutos se informó como T.R.A.M. tiempo de reducción de azul de metileno 30 minutos. Después de la lectura inicial a los 30 minutos se efectuó las lecturas siguientes: cada hora se anotó las lecturas como tiempo de reducción en horas completas entre la inversión triple de los tubos y las lecturas efectuadas al notarse decoloración, por ejemplo: si se observó entre las lecturas de 0,5 a 1,5 horas, se anotó el resultado como T.R.A.M.: 1 hora. Debido a la perdida de color irregular que se puede observar al final de tiempo de lectura se anotó la decoloración de las muestras cuando las 4/5 partes de la porción visible estaban blancas.

Prueba de azul de metileno: $89.53 \%$ de las muestras presentaron un tiempo de reducción de azul de metileno superior a cuatro horas, indicativo de una leche apta para procesos de higienización. El $10.47 \%$ de las muestras presentaron tiempo de reducción menores de 1 hora calificando las muestras de leche como no aptas para consumo humano y procesos industriales. El examen de las muestras se 
realizó según las especificaciones aprobadas por el Ministerio de Protección, 2006 y 2008 para determinar calidad del producto.

\section{ANÁLISIS DE DATOS}

Se hizo uso de la estadística descriptiva para los valores y parámetros que muestran una normalidad tales como producción de leche en general y por grupos de vacas etáreos, y los correspondientes a la determinación de las características fisicoquímicas como densidad, grasa, lactométria y acidez, realizándose pruebas de promedio y mediana cuando los datos presentaban una variación significativa.

La leche se define como el producto de la secreción mamaria normal de animales bovinos, bufalinos y caprinos lecheros sanos, obtenida mediante uno o más ordeños completos, sin ningún tipo de adición, destinada al consumo en forma de leche líquida o a elaboración posterior. La composición y los caracteres organolépticos pueden variar en el transcurso del periodo de lactación distinguiéndose el calostro, el final del ciclo y la correspondiente lactación completa (Ministerio de Protección, 2006; 2008).

Para la comparación de los resultados obtenidos con los análisis de la leche que se produce en Chipaque, se tuvieron en cuenta las características fisicoquímicas de la leche como:

- La densidad es el peso de un volumen dado de leche comparado con el mismo volumen de agua y temperatura. La densidad se mide con un termolactodensímetro calibrado a $15^{\circ} \mathrm{C} / 15^{\circ} \mathrm{C}$. Se calibra con agua a $15^{\circ} \mathrm{C}$, cuya densidad debe ser de $1 \mathrm{mg} / \mathrm{cc}$ y posteriormente se mide a $15^{\circ} \mathrm{C}$ la densidad de la leche, ésta es variable con valores medios entre 1.028 y 1.034 a una temperatura de $15^{\circ} \mathrm{C}$, si esta es tomada a una temperatura mayor o menor es necesario realizar una corrección de +0.2 para la primera o de -0.2 para la segunda. El lactodensímetro es muy utilizado para realizar la medición de esta característica. La densidad de la leche es igual al peso en kilogramos de un litro de leche a temperatura de $15^{\circ} \mathrm{C}$ y depende de la combinación de densidades entre sus diferentes componentes, una leche entera tendría una densidad promedio de 
1.032, mientras que una leche descremada 1.036 (Keating.1986.) La densidad para la leche 15/15, según el Ministerio de Protección (2006; 2008) es: Leche entera: 1.0300-1.0330 gramos/mililitro, leche semidescremada: 1.0310-1.0335 gramos/ mililitro, Leche descremada: $1.0330-1.0360$ gramos/ mililitro.

- La concentración hidrogeniónica $(\mathrm{pH})$, la leche tiene una reacción iónica cercana a la neutralidad, la de vaca es débilmente acida, con un pH comprendido entre 6.6 y 6.8 debido a la presencia de caseína y de aniones fosforito y cítrico, principalmente. El pH es variable en el curso de la lactación y bajo la influencia de la alimentación. En la leche de vaca, deben considerarse como anormales valores inferiores a 6.5 o superiores a 6.9. El calostro tiene un pH más bajo por su elevado contenido en proteínas (Alais, 1985). Las variaciones del pH dependen del estado sanitario de la glándula mamaria, de la cantidad de $\mathrm{CO}_{2}$ disuelto en la leche, del desarrollo de los microorganismos que al desdoblar la lactosa producen acido láctico, y algunos microorganismos alcalinizantes, entre otros (Judkins, 1999).

- La acidez es la suma de cuatro reacciones, tres primeras corresponden a la acidez natural y la cuarta a la acidez desarrollada, donde hacen bajar el pH entre 4 y 5 (Keating, 1986.) La acidez para la leche, según el Ministerio de Protección (2006; 2008) es de: 0.13-0.17.

- La viscosidad de la leche es mayor que la del agua, esto por la materia grasa en emulsión y por las macromoléculas proteicas; las sustancias en solución solo intervienen en una pequeña parte. La viscosidad de la leche entera a $20^{\circ} \mathrm{C}$ es de 2.2 centripoises y el de la leche descremada de 1.2 centripoises (Alais, 1985). La viscosidad se modifica de acuerdo a la homogenización, el tratamiento térmico de la crema que consiste en un recalentamiento seguido de un enfriamiento, y la contaminación de ciertos microbios especialmente los estreptococos lácticos, los cuales elevan la viscosidad del producto.

- El calor específico de la leche es el número de calorías necesarias para elevar un $1^{\circ} \mathrm{C}$ la temperatura de la unidad de peso de la leche. Este valor es más elevado 
que el del agua: Leche completa 0.93-0.94, leche descremada 0.94-0.96, suero de queso 0.97 y grasa $0.40-0.60$ (Keating, 1986.)

- El punto de congelación es constante en la leche, es de $-0.539^{\circ} \mathrm{C}$ como valores promedio, teniendo un rango de -0.513 a $-0.565^{\circ} \mathrm{C}$ Este método permite detectar la adición de agua ya que, al congelarse a $0^{\circ} \mathrm{C}$, influye para que el valor del punto de congelación de la leche se aproxime al del agua. Sobre esta propiedad influyen las sales y la lactosa por encontrarse en solución viscosa (Veisseyre, 1990).

- La calidad higiénica de la leche se mide a través de la prueba de reductasa (Tiempo de Reducción de Azul de Metileno: TRAM), que determina el grado de concentración de bacterias. Menor tiempo de reductasa indica mayor cantidad de bacterias, a mayor tiempo, menor cantidad de éstas.

- La temperatura de ebullición de la leche se inicia a los $100.17^{\circ} \mathrm{C}$ al nivel del mar; sin embargo, pueden inducirse este fenómeno a menor temperatura con solo disminuir la presión del líquido, esta práctica se aplica en la elaboración de leches concentradas al vapor mediante vacío. Este proceso tiene la ventaja de no alterar los componentes de la leche (Alais, 1985).

\section{RESULTADOS}

El sistema doble propósito es utilizado por el $97 \%$ de los predios productores de leche encuestados, las fincas son explotaciones en su gran mayoría que pueden ser catalogadas como minifundios, menores 5 fanegadas (85\%) (Tabla 1). En estos predios el área de pasturas es aproximadamente del $80 \%$, prácticamente no existe el área de bosque siendo inferior a un $5 \%$. Las fincas cuentan con pasturas mejoradas (100\%) siendo el kikuyo (Penisetum clandestinum) el forraje disponible. El número de animales encontrados en el momento de la encuesta fue 624 (100\%) animales distribuidos de la siguiente manera: Vacas lactantes 248 (corresponden al $40 \%)$, vacas horras $62(10 \%)$, novillas de vientre $34(5.45 \%)$, novillas de levante $28(4,5 \%)$, terneras $78(12,5 \%)$, terneros $64(10 \%)$, machos de levante $58(9,29 \%)$, machos de ceba $35(5,6 \%)$ y toros $17(2,7 \%)$ (Figura 1). Siendo las razas predominantes normando puro $(15.7 \%)$, Holstein $(7 \%$,$) criollo (40 \%)$, cruces 
Normando x criollo (30\%), Normando x Holstein (5\%), Holstein x criollo $(0.3 \%)$ y otras (2\%). Otros animales son: caballos 15 , mulares 1 , aves 1.300 aproximadamente, porcinos 35 , ovejas 9 y caprinos 5 .

Respecto al manejo del Hato en la mayoría de las fincas se ordeña una vez al día, realizándose con el ternero al pie en un $90 \%$ y lo realizan en el potrero en el $97 \%$ de los predios encuestados. Promedio tiempo de lactancia: entre 240 y 300 días; edad al destete: al primer día 3\%, entre 8 y 13 meses el $97 \%$. El lugar de ordeño fue en potrero $97 \%$, únicamente el $3 \%$ lo realiza en establo. La comercialización de la leche: se hace en la planta procesadora $60 \%$, intermediario $30 \%$ y el productor $5 \%$.

Se comercializan gran gama de derivados lácteos en paradores ubicados cerca de la vía que conduce de Bogotá a Villavicencio. El volumen semanal es aproximadamente de 5.200 kilos de queso doble crema, campesino 2.200 kilos, cuajada 3.000 kilos, kumis y yogurt 1.000 litros. El productor elabora ocasionalmente cuajada o queso campesino empleando 5-10 litros. Le compran la leche producida en todas las épocas $100 \%$ excepto, algunos como 25 y 31 de diciembre y jueves y viernes santo. El $100 \%$ de los compradores pagan la leche por volumen sin importar porcentaje de grasa ni sólidos totales.

El estado sanitario del lugar donde se efectúa el ordeño, se puede catalogar como regular en un $60 \%$ de las explotaciones, debido a que el lavado de manos se realiza en un $50 \%$ de los casos, aunque el overol y las botas el $100 \%$ del personal en las fincas los utiliza. Es de anotar que lugar de almacenamiento y conservación de la leche presentó condiciones excelentes en el 100\% de los predios. Se aplican vacunas contra la fiebre aftosa $(100 \%)$, carbón sintomático (triple viral) $(100 \%)$, brucelosis $(100 \%$ de las hembras menores 1 año) y peste boba $(0.8 \%)$. La frecuencia de aplicación de productos para controlar parásitos externos es cada mes (40\%), cada 2 meses (45\%), a los 3 meses (10\%), a los 4 meses (5\%). La frecuencia de control en parásitos internos es cada 2 meses (5\%), cada 4 meses (26\%), a los 5 meses (32\%) a los 6 meses (54\%) cada año (3\%). 
Tabla1. Distribución de los predios encuestados

\begin{tabular}{cccc}
\hline Veredas & Predios & Vereda & Predios \\
\hline Cerezos Grandes & 9 & La Ladera & 3 \\
Querente & 8 & Munar & 4 \\
Alto del ramo & 8 & Flórez & 3 \\
La Idaza & 6 & Potrero grande & 3 \\
Hoyas & 5 & Llano de Chipaque & 2 \\
Alto de la cruz & 4 & Cumba & 2 \\
Cerezos Chiquitos $_{1 \text { a } 10 \text { fanegadas }^{1}}$ & 3 & Siecha & 2 \\
$16-23$ fanegadas $^{2}$ & 52 & $11-15$ fanegadas & \\
\hline
\end{tabular}

1,2 y ${ }^{3}$ Corresponden al: 85,11 y $2 \%$ respectivamente de las encuestadas

\section{FIGURA 1. Relación de bovinos por grupos etareos}

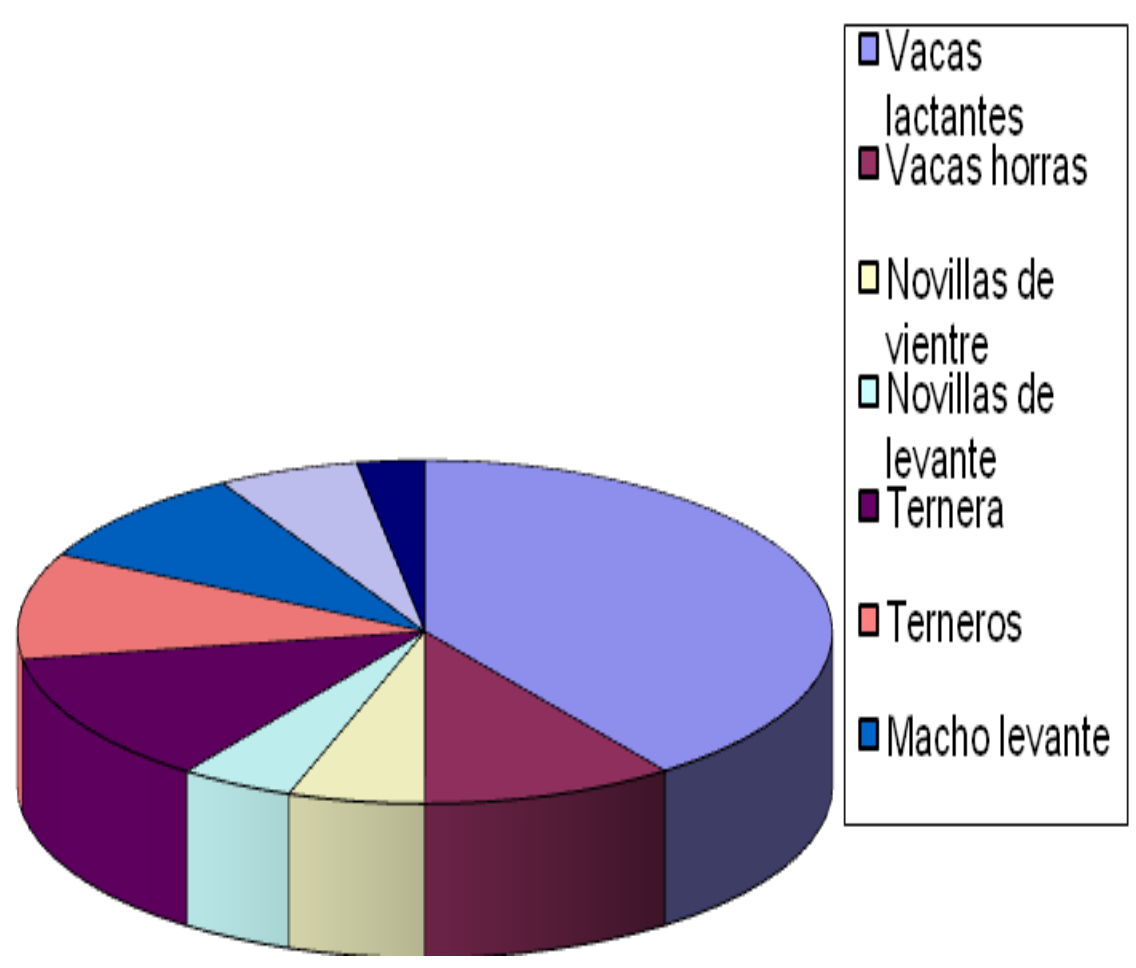




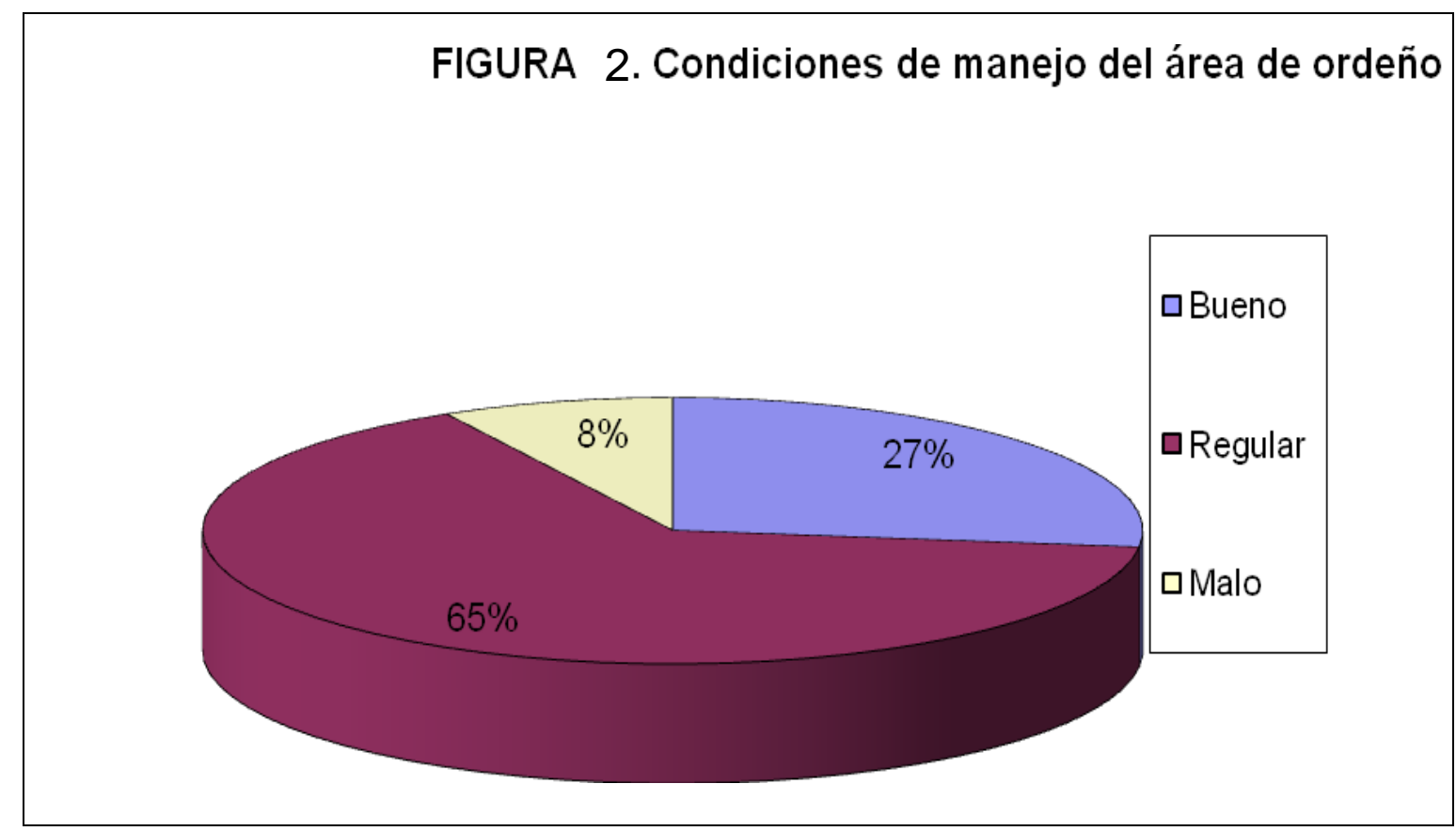

Para las pruebas de tiempo de reductasa, en las cuales se midió indirectamente la calidad microbiológica del producto, se determinó igualmente por estadística descriptiva planteándose la posibilidad de emplear la estadística no paramétrica cuando las variables no presentaron normalidad o no fueron cuantificables.

La densidad presentó parámetros ligeramente superiores a los normatizados por el Ministerio de Protección (2006; 2008), estos son similares a los encontrados en otras regiones de explotaciones doble propósito como la de los Llanos (Mojica, 2004) (Taba 2 y Figura 3). El componente graso presentó valores superiores a los exigidos en el decreto, por lo cual la comercialización por calidad debe favorecer a los productores. A diferencia de los resultados encontrados en otras regiones del país en cuanto a grasa de leche de vacas de raza Holstein, presentaron porcentajes de grasa relativamente altos, cifras similares a las de sus cruces, siendo inferiores los valores para la raza normando (Tabla 2).

La acidez medida como porcentaje de ácido láctico arrojo valores aceptables, dentro de la norma vigente, siendo ideal centrarse en este parámetro para ofrecer un producto competitivo en su aspecto microbiológico, La acidez dependiendo de la raza no es significativamente variable, se infiere que está relacionada con la 
composición porcentual de la leche y el manejo en cuanto a calidad microbiológica en el momento del ordeño. El agua de constitución, fue calculada con base a fórmula matemática, de acuerdo a las recomendaciones del decreto 616 de 2006, encontrando valores aceptables, lo cual permite inferir que es leche con una acidez adecuada para realizar procesos industriales, siendo necesario impedir el crecimiento bacteriano mediante la red de frio. Los valores superan ampliamente las cifras exigidas en la reglamentación siendo estas, similares a las encontradas en otras regiones cuyas explotaciones son de doble propósito (Tabla 2 y Figura 4).

Tabla 2. Análisis físico químico de las muestras leche tomadas en el municipio de Chipaque

\begin{tabular}{ccc}
\hline Prueba & $\begin{array}{c}\text { Resultados promedios } \\
\text { en vacas }\end{array}$ & $\begin{array}{c}\text { Resultados promedios en } \\
\text { cantinas en finca }\end{array}$ \\
\hline Densidad & $1.031,2$ & 1031.4 \\
Acidez & $0.155 \%$ & $0.159 \%$ \\
Lactometría & $8.73 \%$ & $8.9 \%$ \\
Grasa & $3.6 \%$ & $3.62 \%$ \\
Sólidos totales & $12.77 \%$ & $12.52 \%$ \\
Agua de constitución & $87.22 \%$ & $87.42 \%$ \\
\hline
\end{tabular}

Los sólidos no grasos determinados por la prueba de lactométria constituyen un componente, cuyo valor promedio es mayor del $8.4 \%$ normatizado, pero inferior al encontrado en otras regiones donde las explotaciones se enmarcan en el doble propósito. Los sólidos totales arrojaron valores diferentes cuando se tomaron como sumatoria de los SNG y la grasa, que los encontrados por la fórmula de Ritmonch modificada por Kirk et al., (1999), establecidos por el Ministerio de Protección Social, (2006; 2008), pero superando estos valores ampliamente (11.3\%), Los sólidos no grasos se calcularon por formula, presentando variación en cuanto a su valor frente al de lactométria, diferencia considerada en el decreto vigente. La lactométria no presentó diferencias significativas en sus valores al comparar las razas predominantes en la región Holstein, Normando, cruces, y animales criollos. 

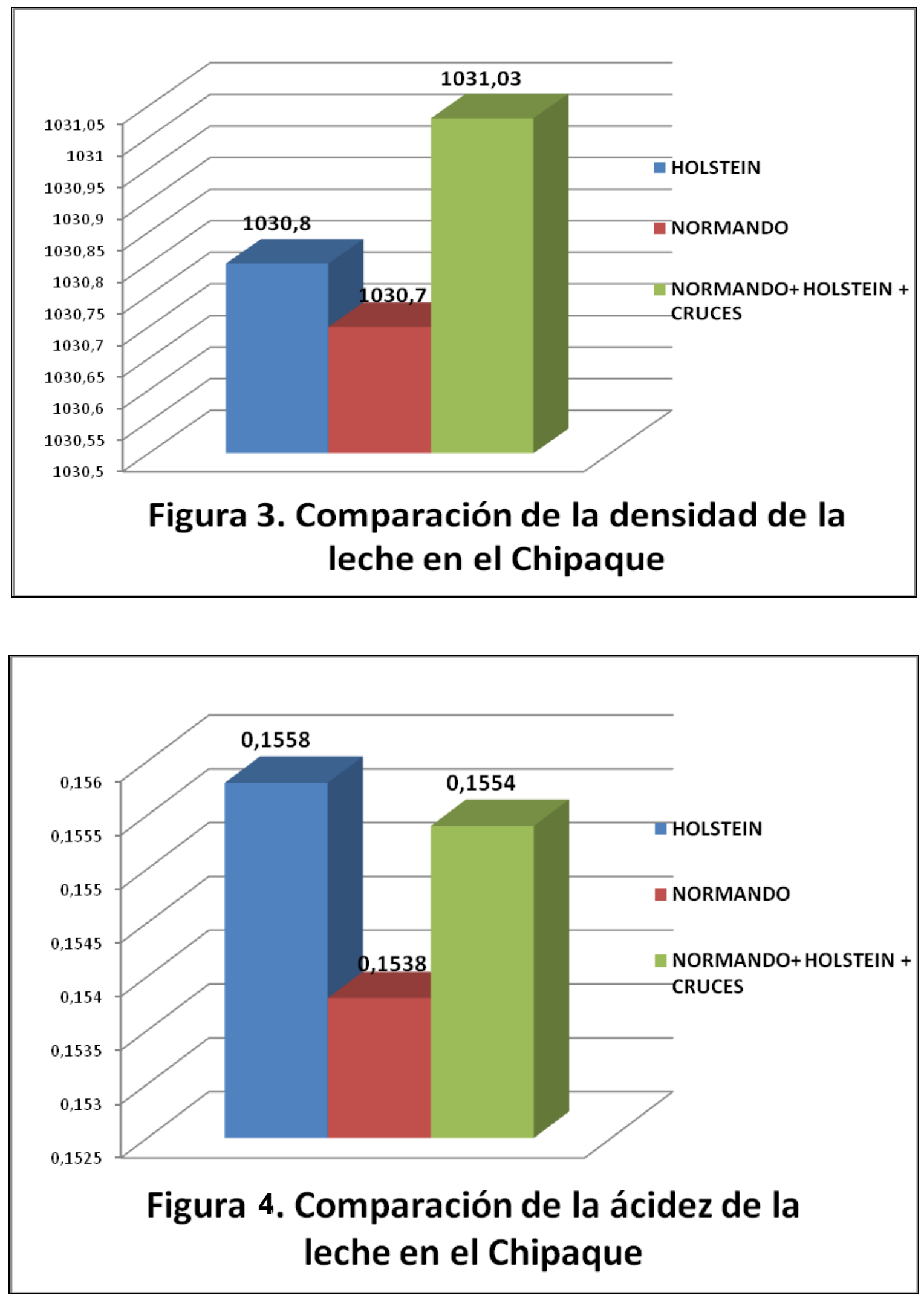

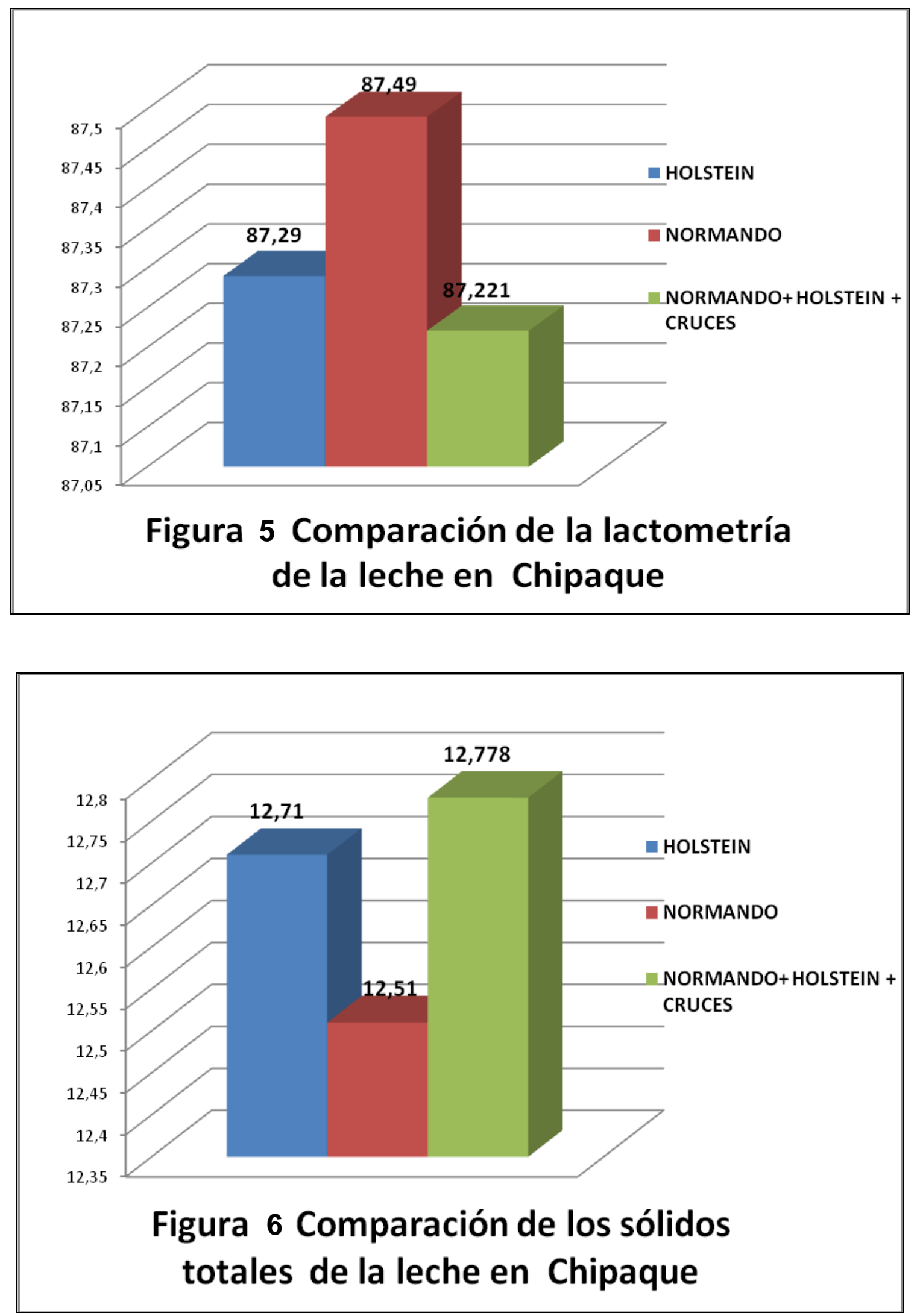
La composición porcentual en cuanto a sólidos no grasos tampoco presentó variaciones significativas, se deduce que es la alimentación un factor influyente en la composición de estos elementos, lógicamente ligado a factores genéticos. Las cifras encontradas son similares a las analizadas en otras regiones donde se explotan ganaderías en el sistema doble propósito, valores superiores a los relacionados en el decreto vigente (Figuras 5 y 6 ).

\section{CONCLUSIONES}

El Municipio de Chipaque tiene aproximadamente 2.300 vacas lactantes dedicadas a la producción comercial de leche bajo el sistema doble propósito y 99 vacas destinadas al sistema de lechería intensiva.

La producción diaria de la leche es aproximadamente 13.800 litros con un promedio de 6 litros/vaca/día; esta producción se mantiene en época de verano e invierno, aunque la producción aumenta en la temporada de lluvias.

La producción de leche se comercializa en un 100\% como leche cruda con destino del $65 \%$ para fábricas de derivados lácteos, el $30 \%$ con intermediarios y un $5 \%$ la vende el productor.

A pesar de contar con un porcentaje significativo $(7 \%)$ de vacas Holstein el manejo dado es el mismo del sistema doble propósito, con ordeño del ternero al lado y cría de machos y hembras; con destete entre los 8 a 13 meses de edad (97\%), solamente el $3 \%$ desteta al primer día.

Los componentes físico químicos de la leche proveniente de vacas de raza normando arrojaron resultados porcentuales ligeramente menores en todos sus componentes en relación con las otras razas de la región como Holstein y los cruces de las mencionadas como también con criollos.

La asistencia técnica programada se aproxima al 100\%, pero ésta es ocasional prestada por el municipio a través de la Umata (90\%), y médicos veterinarios particulares (10\%), adoleciendo de su servicio planificado que conduzca a una tecnificación. 
Se nota poca preocupación por el mejoramiento lechero, cabe resaltar que el programa de vacunación contra brucelosis, fiebre aftosa y carbón sintomático sus coberturas de vacunación se acercan al $100 \%$ de los animales susceptibles, contradiciendo lo reportado en las encuestas donde se atribuye presentación de algunas de estas enfermedades, a pesar esas coberturas de inmunización.

El propietario del predio, en la mayoría de las veces es el administrador, se presenta en el $95 \%$ de las fincas encuestadas, por ser la principal fuente de ingreso familiar. Las buenas prácticas de manejo recomendadas en el decreto 616 del 2006 no se cumplen en alto porcentaje, se registró que el $41 \%$ de los operarios estaban en condiciones aceptables para manipular un alimento y el 59\% no reunían las condiciones adecuadas.

El tipo racial se puede anotar que en el momento de la encuesta el $100 \%$ de las explotaciones carecen de registros técnicos, constituyendo un factor negativo que reduce en la relación costo beneficio los factores contables y económicos la implementación proporcionada no es la más adecuada.

Es importante resaltar la calidad físico-química encontrada en esta investigación la cual arroja un $12.77 \%$ de sólidos totales y un $87.23 \%$ de agua de constitución.

\section{RECOMENDACIONES}

Las entidades que a través de las secretarias municipales de Agricultura prestan asistencia técnica se debe programar para estas explotaciones, haciendo hincapié, en el buen manejo de las praderas, nutrición programas preventivos sanitarios, enseñando y ejecutando con el productor la forma eficiente de llevar registros para mejorar la producción, estabilidad ofreciendo un producto único de buena calidad.

La producción de leches en promedio 6 litros vaca/día, debe incrementarse sin una desmejora en el estado corporal y desarrollo de los terneros. Debe realizarse un plan de vermifugación de acuerdo a la finca donde contemple bajar la carga parasitaria, económico, y eficiente. Se hace necesaria una mayor diversificación 
de las praderas realizando asociaciones de gramíneas y leguminosas. Las asociaciones a través de cooperativas debe ser un programa fundamental para defender los intereses y mejorar la calidad además de tener un fácil acceso a la asistencia técnica exigiendo que esta sea programada y no ocasional.

Debe estimularse por parte del gobierno municipal el establecimiento de centros de acopio y redes de frío.

El pago por calidad, y los programas de buenas prácticas de manufactura se debe implementarse por las secretarias de agricultura, salud departamental y municipal.

\section{BIBLIOGRAFÍA}

1. Alcaldía Municipal de Chipaque. Esquema de ordenamiento territorial (EOT), 2003-2007.

2. Alais C. Ciencia de la leche. Principios de técnica lechera. Editorial Reverte S.A. Barcelona España. 1985.

3. Cámara de Comercio de Bogotá. Caracterización económica y empresarial. 49 [Consultado 14-11-2011]

Disponible: http://camara.ccb.org.co/documentos/6236 caracteriz empresarial oriente.pdf

4. Concejo Nacional Lácteo. Documento de trabajo. 2003. Disponible en: http://www.dnp.gov.co/archivos/documentos/DDE Desarrollo Emp Industria/L acteos.pdf

5. Espinel G.; Martínez C.; González H. La cadena de lácteos en Colombia. Una mirada global de su estructura y dinamica.1991-2005. Documento de trabajo No. 74. Ministerio de Agricultura y desarrollo rural observatorio agrocadenas Bogotá, Colombia. 2005.

6. Judkins $\mathrm{H}_{\text {.; }}$ Keener $\mathrm{H}$. La leche su producción y procesos industriales. $1^{\mathrm{a}} \mathrm{Ed}$. Compañía editorial continental. S.A. México D.F. 1999.

7. Keating P.; Gaona H. Introducción a la lactología. Editorial Limusa México. 1a Ed. 1986.

8. Kirk RS, Sawyer R, Egan H. 1999. Composición y análisis de los alimentos de Pearson. Ed. Continental. Distrito federal, México. 1999: 777.

9. Luquet MF. Leche y productos lácteos. Editorial Acribia S.A. Zaragoza España. 1993.

10. Martínez M. Escuela de mayordomía. Producción de ganado de carne y doble propósito. FEDEGAN, fondo de Ganaderos del Meta, SENA. 2003.

11. Ministerio de la Protección Social. Decreto número 616 por el cual se expide el Reglamento técnico sobre los requisitos que debe cumplir la leche para el consumo humano que se obtenga, procese, envase, transporte, comercializa, expenda, importe o exporte en el país. 08-02-2006:32. Disponible: http://www.sinigan.gov.co/Portal/Portals/0/2006D616.pdf 
12. Ministerio de la Protección Social. Decreto 3411 de 2008 Por el cual se modifica parcialmente el Decreto 2838 de 2006, modificado parcialmente por el Decreto 2964 de 2008, y se dictan otras disposiciones. Diario Oficial No. 47.108 de 10 de septiembre de 2008. Disponible: http://www.avancejuridico.com/actualidad/documentosoficiales/2008/47108/d3 411008.html

13. Mojica C J. Prospectiva tecnológica e industrial para el desarrollo de la cadena láctea. Universidad Externado de Colombia. Bogotá 31 de Mayo de 2004.

14. República de Colombia. Perfil de la cadena Láctea. Ministerio del Comercio Exterior. 2001

15. Roldan D.; Tejada M.; Salazar M. La cadena Láctea en Colombia. Ministerio de Agricultura y Desarrollo Rural. Bogotá Colombia. Noviembre 2001.

16. Spreer E. Lactología Industrial. Editorial Acribia. Zaragoza España. 1975.

17. Valerie R. Principios y fundamentos de leche. Editorial acribia. Zaragoza España. 2001.

18. Veisseyre R. Lactología técnica. 2 $2^{\mathrm{a}}$ Ed. Editorial acribia Zaragoza España.1990. 